\title{
Effect of Reactor Pressure on Electrical and Structural Properties of Diamond Films Grown by Hot-Filament CVD
}

\author{
M. Ullah ${ }^{a, b, *}$, E. Ahmed ${ }^{a}$ AND A.M. RANA ${ }^{a}$ \\ ${ }^{a}$ Department of Physics, Bahauddin Zakariya University, Multan-60800, Pakistan \\ ${ }^{b}$ present address: Department of Physics, G.C. University Faisalabad Layyah Campus, Layyah, Pakistan \\ (Received March 11, 2014; in final form March 30, 2016)

\begin{abstract}
Polycrystalline diamond films with preferred (111) and (222) facets were fabricated inside hot filament che-
\end{abstract} \\ mical vapour deposition reactor on silicon wafers using a mixture of $1 \%$ methane in hydrogen at various reactor \\ pressures ranging from 10 to 50 mbar. Regarding characterization of diamond films, internal texture, surface \\ morphology, quality of diamond and electrical conductivity were investigated using X-ray diffraction, scanning \\ electron microscopy, the Raman spectroscopy and four-point-probe van der Pauw techniques, respectively. Results \\ of these studies demonstrate that polycrystalline diamond structure is grown in random orientation with (111) \\ facet being dominant showing sharp grain boundaries. Moreover, growth rate was found to increase with pressure \\ up to 20 mbar and then decreased for further rise in pressure. That is why grain density is high with relatively \\ smaller grains at higher pressures caused by higher nucleation rates. In contrast, electrical resistivity decreased \\ $\approx 3$ orders of magnitude showing a minimum at $2.9 \times 10^{6} \Omega \mathrm{cm}$ as pressure was increased in the reactor. Reactor \\ pressure during film growth resulted in poor surface morphology, absence of $s p^{3}$ bonds and low resistivity. Hence, \\ decrease of resistivity makes diamond films desirable for many electrical applications in semiconducting/electronic \\ devices.
}

DOI: 10.12693/APhysPolA.131.1419

PACS/topics: HFCVD, electrical properties, diamond films, growth, reactor pressure

\section{Introduction}

High hardness, superior transparency, highest thermal conductivity, high electron and hole mobility, negative electron affinity, high breakdown field, and unique semiconducting characteristics are the matchless properties of diamond that are maximizing its applications in mechanics, optics, and electronics $[1,2]$. However, its wide band gap limits its applications in electronics unless the charge carriers are incorporated into it $[3,4]$. Furthermore, electrical resistivity of diamond films provides useful information for their use as cooling materials in electronic devices [5]. For semiconducting applications, low resistive and good quality diamond films with fine grains are required. In order to meet such requirements, various parameters such as deposition pressure, insertion of various gases, gas flow rates, substrate temperature, doping of metallic species, etc. can be applied. Regarding electrical resistivity, there was noticed a substantial decrease by boron doping [4] and due to the presence of nondiamond components [6]. Similarly, the insertion/incorporation of gases such as nitrogen into the diamond lattice can produce semiconducting and even superconducting diamond films [7], while synthesis of thin film diamond involves the use of a hydrocarbon precursor gas, typically methane diluted in hydrogen by chemical vapor deposition (CVD) [8-10]. Among various CVD methods, hot filament CVD (HFCVD) is now the most commonly used technique due to its relatively low

*corresponding author; e-mail: mahtabullah@yahoo.com cost and the ability to scale up. Various gas species formed on and near the filament and their transport to substrate play important roles in HFCVD diamond film growth [11]. However, transport of active species is affected by the deposition pressure, temperature of the filament, composition of the incoming gases and the extent of chemical reactions on and near the filament. The deposition pressure is important because it sensitively changes both the dynamics and the chemical reaction kinetics of gas phase among various gas species in a CVD reactor [12]. However, it was usually applied in the range from several tens to several hundred mbar for HFCVD diamond film growth. This yields diamond nucleation density of $10^{7}-10^{8} \mathrm{~cm}^{-2}[13,14]$. Diamond films with high nucleation density of $10^{10}-10^{11} \mathrm{~cm}^{-2}$ have also been synthesized by Makris et al. [15] at 29.5 mbar and by Pecoraro et al. $[16]$ at $\approx 15$ mbar by applying a negative bias to the substrate. Low pressure is also effectively helpful in increase of the diamond nucleation density. Lee et al. [17] and Kang et al. [18] reported the high density $\left(10^{10}-10^{11} \mathrm{~cm}^{-2}\right)$ of diamond nucleation on mirror polished silicon substrates under very low pressure (0.1 mbar to 1.33 mbar). Similarly, Yang et al. [19] have deposited diamond thin film by graphite etching through hydrogen as carbon source in HFCVD reactor without plasma discharge. Moreover, high quality diamond films have also been deposited at temperatures as low as $250^{\circ} \mathrm{C}$ using microwave plasma reactor [20]. Dependence of the concentration of atomic hydrogen on the pressure in a region between 7 and 73 mbar was investigated via REMPI by Smith et al. [21]. On the other hand, nanocrystalline diamond (NCD) films on silicon have also 
been synthesized at low temperatures of $450-550{ }^{\circ} \mathrm{C}$ and low pressure of $\approx 9$ mbar by HFCVD in $\mathrm{CH}_{4}+\mathrm{H}_{2}$ mixture by Tianliang Hao et al. [22] and by Schwarz et al. [23] employing a $1 \% \mathrm{CH}_{4}$ in $\mathrm{H}_{2}$ gas mixture at pressure from 50 to 1.25 mbar. Several diamond growth models have also been tested by various researchers to explain the pressure dependence of the growth rate [17, 24-26].

In this work, a study of polycrystalline diamond grown on (100) silicon substrates in a HFCVD system at various pressures (up to 50 mbar) using a mixture of $1 \%$ methane in hydrogen is reported. The influence of pressure on the evolution of diamond grain orientations and textured growth of diamond thin films has been systematically investigated by scanning electron microscopy (SEM), $\mathrm{X}$-ray diffraction (XRD), and the Raman spectroscopy. It is not out of place to mention that the relationship between the diamond film growth rate and the deposition pressures as well as the decrease of resistivity at various deposition pressures measured by four-point probe current-voltage technique are discussed.

\section{Experimental}

Polycrystalline diamond films were deposited on circular Si (100) wafers $(\Phi=10 \mathrm{~cm})$ as substrates using HFCVD technique. Before deposition these wafers were ultrasonically cleaned in ethanol, de-ionized water, and HF to remove any oxide layer. Silicon substrates on $8 \mathrm{~cm}$ molybdenum holder were placed inside the reaction chamber. In addition, hydrogen gas mixed with $1.0 \%$ methane using diverse pressures between 10 to 50 mbar was used. The source gases $\left(\mathrm{CH}_{4}+\mathrm{H}_{2}\right)$ were thermally activated by eight co-planar tungsten filaments $(0.5 \mathrm{~mm}$ thick) separated by $5 \mathrm{~mm}$ spacing. Ratio of the gases was controlled by precision mass flow controller. Deposition process was carried out for $\approx 20 \mathrm{~h}$ at respective temperatures of about $2800{ }^{\circ} \mathrm{C}$ and $900^{\circ} \mathrm{C}$ for the filament and the substrate as measured by thermocouples placed close to them. The deposition parameters set for each diamond film are presented in Table I. The as-grown films were examined

TABLE I

Different diamond thin film parameters.

\begin{tabular}{c|c|c|c}
\hline \hline $\begin{array}{c}\text { Deposition } \\
\text { pressure } \\
{[\mathrm{mbar}]}\end{array}$ & $\begin{array}{c}\text { Resistivity } \\
{\left[\times 10^{7} \Omega \mathrm{cm}\right]}\end{array}$ & $\begin{array}{c}\text { Growth rate } \\
{[\mu \mathrm{m} / \mathrm{h}]}\end{array}$ & $\begin{array}{c}\text { FWHM of Raman } \\
1332 \mathrm{~cm}^{-1} \text { peak }\end{array}$ \\
\hline 10 & 105.00 & 0.054 & 10.54 \\
20 & 72.40 & 0.125 & 09.52 \\
30 & 01.17 & 0.035 & 14.36 \\
40 & 00.29 & 0.048 & 10.21 \\
50 & 01.57 & 0.034 & 14.32
\end{tabular}

by SEM (LEO 1550 with acceleration voltage of $10 \mathrm{kV}$ ) and X-ray diffraction (D500, $\mathrm{Cu} K_{\alpha}, \lambda=0.1541 \mathrm{~nm}$ ) at room temperature. The Raman spectra were analyzed with a backscattering geometry with visible excitation [27] of $514 \mathrm{~nm}$ lines of an $\mathrm{Ar}^{+}$laser using Renishaw 2000 micro-Raman system. A laser spot of $10 \mathrm{~mW}$ was focused on the sample surface using a 20X objective with short-focus working distance. The resistivity was investigated by four-point probe current/voltage in the van der Pauw [28] geometry at room temperature with maximum voltage of \pm 100 volts. Current and voltage were measured by a semiconductor device analyzer (Agilent B1500A).

\section{Results and discussion}

\subsection{Structural studies}

Figure 1 shows representative XRD patterns of diamond thin films with a typical diamond (cubic) structure. The characteristic (111) and (222) peaks of diamond structure are clearly visible at $2 \theta$ values of $43.9^{\circ}$ and $94.96^{\circ}$ along with $(220),(311)$ reflections. It is noticed that higher pressures lead to considerable decrease in the intensity of these (220) and (311) diamond signals. In addition, no (311) peak was observed at pressures $\geq 30$ mbar (see Fig. 1). This fact leads to the preferred

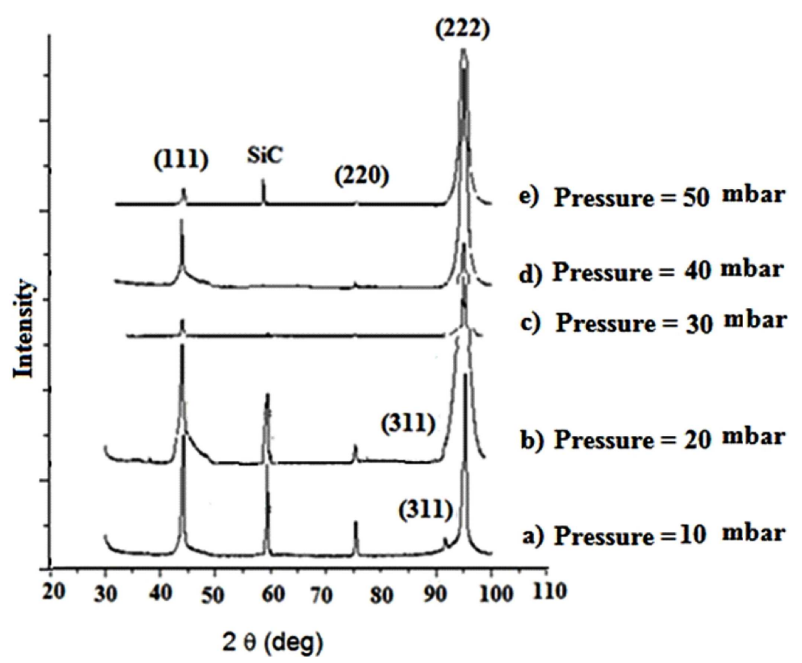

Fig. 1. XRD patterns of five diamond films deposited at various pressures: (a) 10 mbar, (b) 20 mbar, (c) 30 mbar, (d) 40 mbar, (e) 50 mbar.

growth of (111) and (222) crystals of diamond on increasing reactor pressure. An additional reflection related to $\mathrm{SiC}$ was also noticed in some patterns. This reflection is an indication of the chemical reaction of depositing carbon atoms with Si wafer (substrate). The FWHM of the observed diamond reflections can be used as a qualitative measure of the degree of crystallinity within the diamond deposit. The FWHM of XRD reflections depends on both the grain size and the crystallinity, so it possesses the tendency to become narrow when grain size becomes large. A comparison of the (222) diamond peak observed for a series of diamond films depositions at various pressures from 10 to 50 mbar revealed a decrease in intensity with some oscillatory trend (see Fig. 2). Figure 2 also illustrates the intensity of the XRD (222) reflection as a function of deposition pressure depicting 


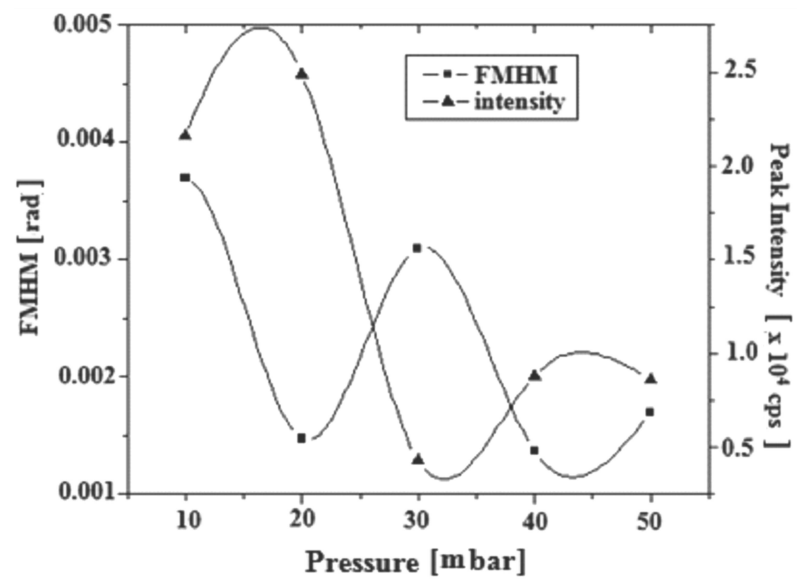

Fig. 2. FWHM and peak intensity of the (222) plane as determined from XRD patterns of HFCVD diamond films deposited at various pressures.

oscillatory trend and clearly demonstrating some improvements in terms of grain size of the diamond polycrystals with the pressure, whilst greater pressure leads to some degradation in grain size. This behavior may be caused by high nucleation rate but low growth rate. Moreover, the varying trend of preferred orientations and texture of the deposited diamond films may lead to the oscillatory trend noticed in FWHM and peak intensity. The present findings are looking much consistent with those of Yang et al. [29]. From these experimental findings, it can be concluded that an appropriate pressure can be selected to improve and achieve good quality of diamond crystals.

\subsection{Effect on morphology}

SEM micrographs of five different diamond films grown at various pressures are shown in Fig. 3 and can be used for quality and internal structure analyses. At reactor pressure of 10 mbar randomly-oriented diamond crystals depicting rough surfaces and mean crystallite size of $\approx 0.9 \mu \mathrm{m}$ were detected as seen in Fig. 3a, while Fig. 3b shows some isolated crystals and some connected crystals of $\approx 2.5 \mu \mathrm{m}$ diameter having (111) facet dominant, which were grown at 20 mbar pressure. The presence of isolated and disconnected crystals might be associated with the fact that the Si wafer surface had not been properly etched prior to CVD. But with the rise of pressure from 30 mbar to 50 mbar, relatively uniform and smoother films of polycrystalline diamond grains were obtained possessing well-facetted shape with average grain size in the range from $0.7 \pm 0.02 \mu \mathrm{m}$ to $1.0 \pm 0.02 \mu \mathrm{m}$ (Fig. $3 \mathrm{c}-\mathrm{e}$ ).

Similar type of diamond crystal morphology was observed by Schwarz et al. [23] who also noticed the maximum (or large) sized crystals of $\approx 2 \mu \mathrm{m}$ at 20 mbar pressure but at a pressure of 50 mbar diamond grain size decreased to $\approx 1 \mu \mathrm{m}$. They also observed the secondary nucleation on diamond crystals which degrade the quality of diamond crystals but in the present case no secondary nucleation was noticed which is a good indication of the high quality of diamond crystals. They associated the largesized crystal to the suppression of secondary nucleation.

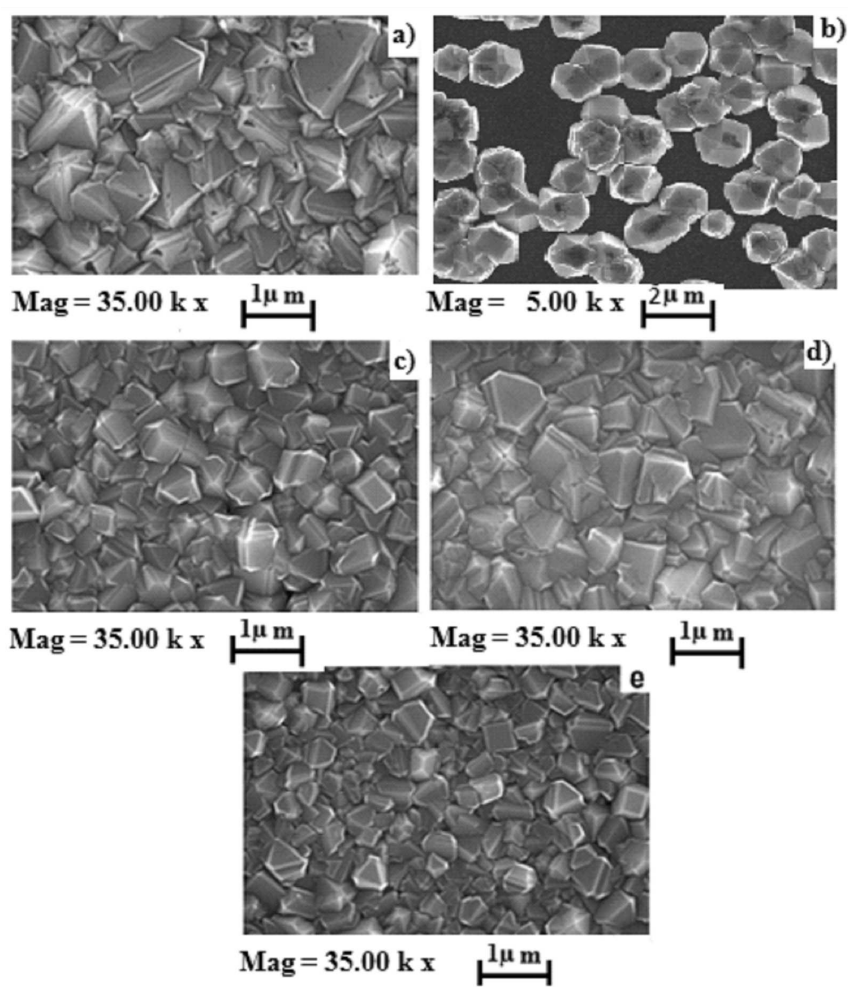

Fig. 3. SEM micrographs of five diamond films deposited at various pressures: (a) 10 mbar, (b) 20 mbar, (c) 30 mbar, (d) 40 mbar, (e) 50 mbar.

X. Liang et al. [30] demonstrated that with the decrease of reactor pressure, size of the diamond grains also decreased and even at very low pressure of 1.25 mbar nanosized diamond crystallite were detected. They also gave the same reasoning of the suppression of secondary nucleation at high pressures to form large crystallites/grains. On the other hand, the nanosized grains were caused by the enhanced secondary nucleation at very low pressure. T. Hao et al. [22] also grew nanosized crystals at low pressures by enhancing the nucleation rate through a four step process. As in the present study the lowest pressure used was 10 mbar with $\approx 20 \mathrm{~h}$ of deposition so $\mu \mathrm{m}$-sized crystals were observed.

Figure 4 depicts the behavior of diamond grain size and grain density as a function of chamber pressure. In both cases an oscillatory but opposite behavior is noticed as both are reciprocal to each other. The grain density was calculated using the relation [31]:

$$
N_{v}=2.4150 \sqrt{\bar{a}}-1.4552 \bar{l},
$$

where $\bar{a}$ is the average grain area on a random twodimensional section and $\bar{l}$ gives the average intercept length of a random test line with grain surface. Figure 4 shows that except at 20 mbar pressure, diamond grain density almost shows an increasing trend with rise of pressure. It means that diamond growth rate is relatively high at low pressures up to 20 mbar (demonstrating some single and isolated crystals as obvious from Fig. 3b) but pressures greater than 20 mbar suppress the diamond 


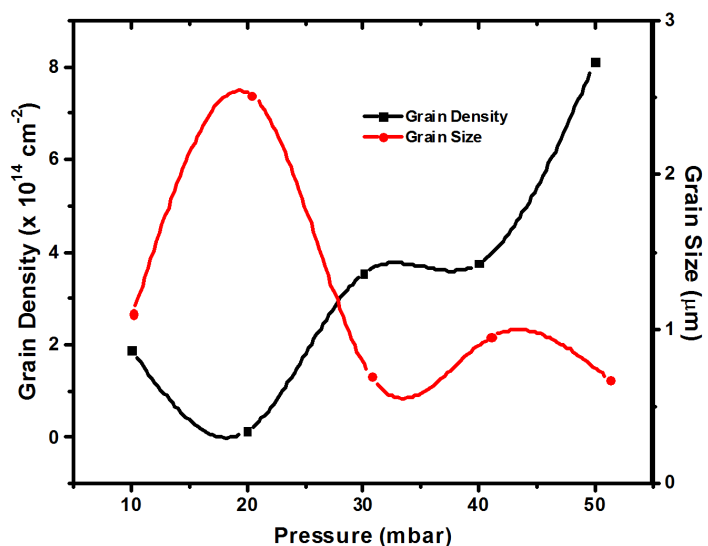

Fig. 4. Diamond crystallite size and density as a function of chamber pressure as determined from SEM micrographs.

growth rate but increase the nucleation rate that is why diamond grains density is higher with relatively smaller and fine crystallite sizes at these pressures. In addition, the high value of grain density leads to high nucleation, which might lead to nanosized crystals but due to large deposition time $\mu \mathrm{m}$ sized crystals were the result. Also the present nucleation rates are relatively higher than those already noted by other researchers [13-18]. Thus it can be concluded that reactor pressure poses large effects on the diamond morphology and grain size. Such behavior of diamond growth seems in close agreement with that of Hirakuri et al. [32]. Moreover, almost all the films were noticed to grow uniformly and smoothly at all pressures with polycrystalline grains so that such polycrystalline films can be grown using HFCVD system at relatively large substrate areas.

\subsection{Effect on crystal quality}

For the comparison of crystal quality and the study of any impurities present in the diamond films deposited at different pressures, the Raman spectra of these films were recorded at room temperature and are shown in Fig. 5. In the spectrum of diamond film deposited at 10 mbar, a diamond peak exists at $1339 \mathrm{~cm}^{-1}$. This Raman peak at $1339 \mathrm{~cm}^{-1}$ indicates a shift as compared to the natural diamond peak $\left(1332 \mathrm{~cm}^{-1}\right)$, and this shift may be due to the presence of compressive stresses at low pressure caused by the non-uniform growth of diamond crystals. The weak $G$ - and $D$-peaks of graphite are situated at $1350 \mathrm{~cm}^{-1}$ and $1475 \mathrm{~cm}^{-1}$, respectively. Two more peaks located at $1140 \mathrm{~cm}^{-1}$ and $963 \mathrm{~cm}^{-1}$ are observed among which $1140 \mathrm{~cm}^{-1}$ peak can be associated with amorphous network as reported in the literature $[33,34]$ or it might be due to Ne lamp whereas the Raman signal at $963 \mathrm{~cm}^{-1}$ might be a 2 nd-order silicon peak. The spectrum observed at 10 mbar is similar to that of Schwarz et al. [23] observed at 3 mbar. At 20 mbar pressure, diamond peak has been shifted back to its natural position i.e. $1332 \mathrm{~cm}^{-1}$ but with very high intensity. Moreover, the $G$ - and $D$-peaks have reduced in intensity

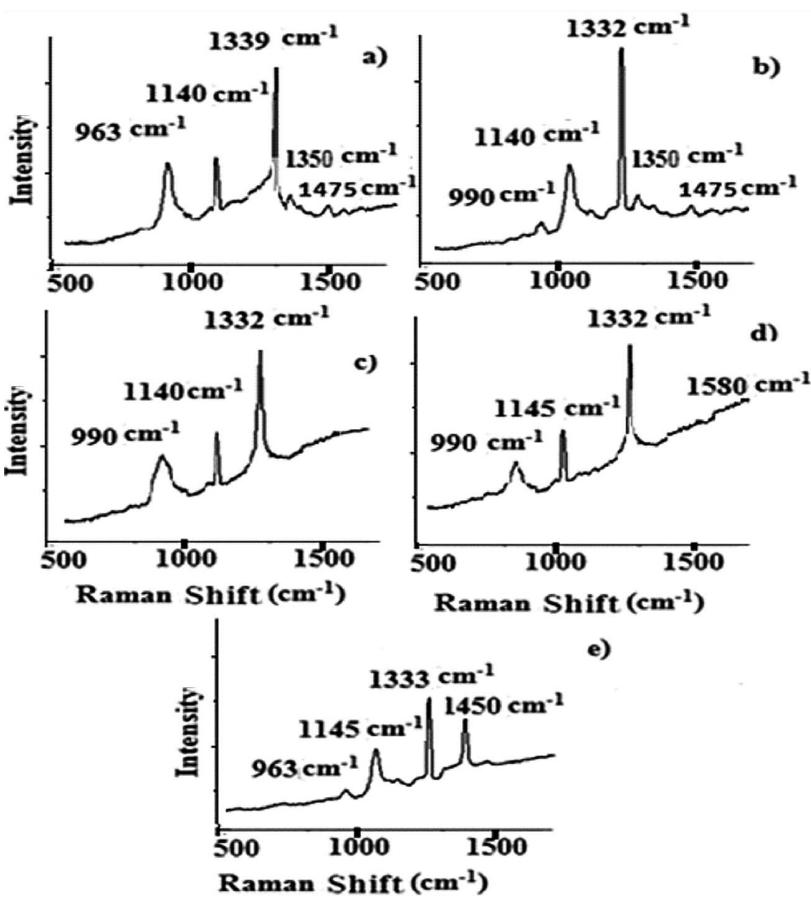

Fig. 5. Raman spectra of five diamond films grown at various pressures: (a) 10 mbar, (b) 20 mbar, (c) 30 mbar, (d) 40 mbar, (e) 50 mbar.

at this pressure leading to an improvement in diamond crystal quality. This may be due to the increasing generation of atomic hydrogen caused by the extension of residence time, which is capable of enhancing the removal of non-diamond components [32]. The amorphous peak is still located at the same position of $1140 \mathrm{~cm}^{-1}$ while 2nd-order silicon peak has shifted to $990 \mathrm{~cm}^{-1}$ (see Fig. 5b). Such behavior may be caused by the isolated diamond crystals observed only at this pressure as most of the surface is $\mathrm{Si}$ and these results match with those of Yang et al. [29]. At much higher pressures of 30 and 40 mbar, the diamond peak remains at its natural position. But the peaks at $1350 \mathrm{~cm}^{-1}$ and $1475 \mathrm{~cm}^{-1}$ have disappeared. This is possibly the consequences of the etching process due to which amorphous carbon peaks have strongly been reduced as shown in Fig. 5d,e. However, an extra weak peak at $1580 \mathrm{~cm}^{-1}$ is observed at a pressure of 40 mbar, such a Raman vibration was also noticed by Schwarz et al. [23] at 3 mbar pressure. This is actually the $G$-peak which is related to the highly oriented graphite phase (HOPG). The diamond peak at pressure of 50 mbar has again slightly shifted to $1333 \mathrm{~cm}^{-1}$ (Fig. 5e). Moreover, the Raman peaks at $\approx 1350 \mathrm{~cm}^{-1}$ and $1450 \mathrm{~cm}^{-1}$ have reappeared causing the increase of non-diamond phase again. From the above results it can be concluded that the Raman spectra also supports the fact that the quality of diamond strongly depends on the reactor pressure, because the generation of atomic hydrogen sharply decreases with increase of pressure [17].

The FWHM values obtained for the Raman $\approx$ $1332 \mathrm{~cm}^{-1}$ diamond peak presented in Table I also 
support our results of the crystal quality with increasing pressure. The FWHM results also confirm that the highest quality diamond crystals grow at deposition pressure of 20 mbar. It is noted that where the growth rate is higher, FWHM values are lower and so diamond crystals have relatively larger sizes. But at those pressures where FWHM values are higher, good quality diamond crystals are the consequences.

\subsection{Effect on electrical resistivity}

Figure 6 shows electrical resistivity of diamond thin films (deposited at various pressures from 10 to 50 mbar) measured by four point probe $I-V$ technique in van der Pauw geometry at room temperature with maximum voltage of \pm 100 V. From the results presented in Table I

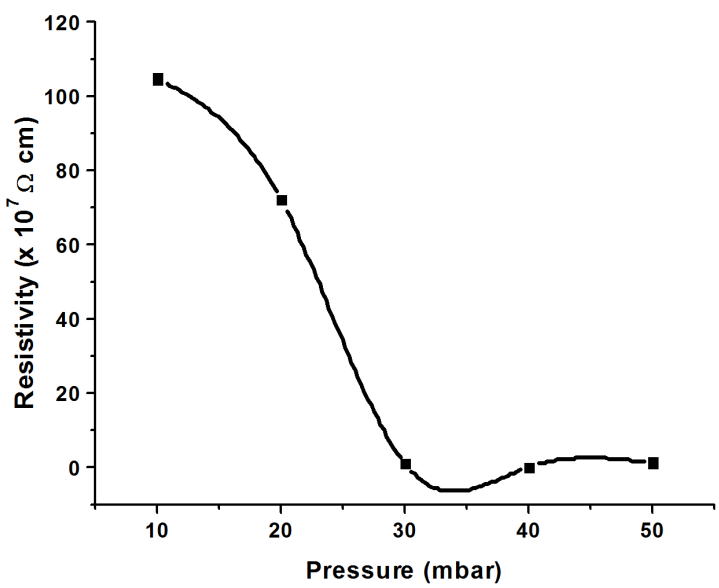

Fig. 6. Electrical resistivity as a function of reactor pressure.

and Fig. 6, it is clear that resistivity decreases rapidly up to a pressure of 30 mbar and then slowly with further increase of chamber pressure. The decrease of resistivity might be due to the causes of grain edge and contamination scattering at lower deposition pressures [35]. But as diamond grain density increases at pressures $\geq 30$ mbar, see Fig. 3, increase of the grain boundary area, consequently reduces the conductivity and causes the observed slow decrease of resistivity with pressure. The behavior of resistivity with pressure also supports the findings obtained using SEM, XRD and the Raman spectroscopy. Minglong Zhang et al. [6] deposited diamond films at a pressure of 40 mbar under different conditions such as annealing etc. and found that resistivity varied in the range of $10^{10}-10^{11} \Omega \mathrm{cm}$ at a voltage of $50 \mathrm{~V}$. Such value of electrical resistivity of diamond films is very much higher as compared to resistivity value noted at 40 mbar pressure in present study, i.e. $2.9 \mathrm{M} \Omega \mathrm{cm}$. Present values of resistivity are about 4 to 5 order of magnitude smaller. It is known that the change of resistivity can be attributed to presence of the non-diamond component as well as hydrogen contamination of the films which are inevitably present in HFCVD diamond films [36]. In addition, the deviation of resistivity may be due to the influence of internal or external stresses [37] or the interfacial layer ( $\mathrm{SiC}$ as observed through XRD in Fig. 1) effect between the films and Si substrate, related to the substrate pretreatment and growth parameters. In addition, the orientation or texture of the films is also an important parameter affecting the electric properties [38].

\subsection{Effect on growth rate}

The pressure dependence of growth rate (as determined from the cross-sectional view using SEM) of diamond crystals is displayed in Fig. 7 at a substrate temperature of $900^{\circ} \mathrm{C}$ and indicates that growth rate increases strongly with increasing pressure up to 20 mbar and then decreases with further rise of pressure. The growth rate

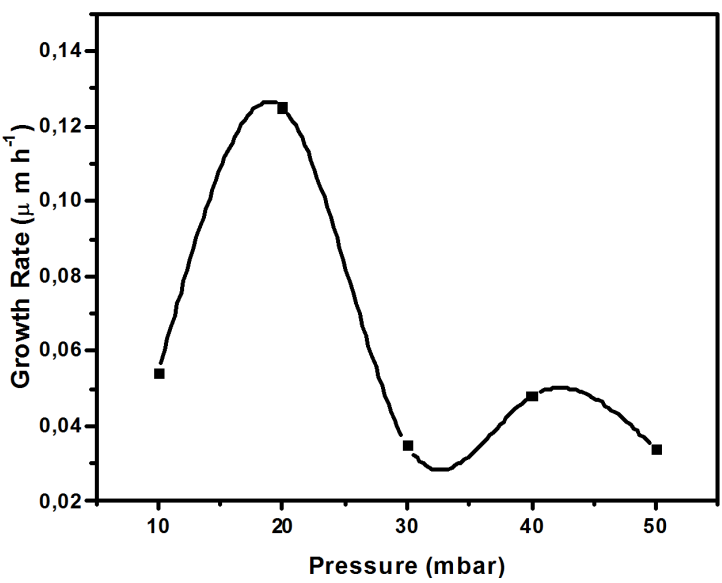

Fig. 7. Diamond polycrystals growth rate as a function of deposition pressure.

shows a maximum at $20 \mathrm{mbar}(0.125 \mu \mathrm{m} / \mathrm{h})$ and a minimum at $50 \mathrm{mbar}(0.034 \mu \mathrm{m} / \mathrm{h})$. Thus, the highest growth rate (at $20 \mathrm{mbar}$ ) is almost 4 times the slowest growth rate (at 50 mbar). Behavior of growth rate for pressures $>20$ mbar is in agreement with that observed by Schwarz et al. [23] however magnitudes of growth rate differ significantly. Schwarz et al. [23] found the fastest growth rate $(0.7 \mathrm{\mu m} / \mathrm{h})$ at $3 \mathrm{mbar}$ while growth rate at 50 mbar was only $0.2 \mu \mathrm{m} / \mathrm{h}$. Brunsteiner et al. [39] found maximum growth rate at 27 mbar with a slightly slower growth rate at a pressure of 7 mbar. These results disagree with growth rates observed in the present investigations. A possible explanation of this disagreement could be different deposition conditions based on experimental setup such as use of $8 \mathrm{~W}$ (tungsten) filaments $(\Phi=0.5 \mathrm{~mm}$ ), filament temperature, filament-substrate distance, gas flow rate etc. Xingbo Liang et al. [30] also demonstrated that the growth rate first rose then fell down with the increasing growth pressure, featuring a maximum $(0.6 \mu \mathrm{m} / \mathrm{h})$ at 28 mbar $(2.8 \mathrm{kPa})$, while they found the minimum growth rate $(0.11 \mu \mathrm{m} / \mathrm{h})$ at $1.25 \mathrm{mbar}(0.125 \mathrm{kPa})$. They claimed that their results appear different from the results reported by Schwarz et al. [23], but in agreement with those reported by Brunsteiner et al. [39]. Harris and Weiner [40] also performed similar studies to illustrate the pressure effect on the kinetics of diamond films 
grown by HFCVD and found that the growth rate increased with pressure between 12 and 27 mbar. Keeping in mind all the presented data and facts, it can be concluded that there are some discrepancies in the value of reactor pressure for the maximum growth rate, however, there is a common feature noted in all the investigations that the growth rate first increases and then decreases with the reactor pressure, featuring a maximum point at a specific pressure.

\section{Conclusions}

The diamond films of uniform thickness were successfully grown on Si-substrates with single/polycrystalline grains at various deposition pressures using HFCVD. The system can be used to deposit such polycrystalline diamond films with relatively large film areas. Growth rate generally decreases with the increase of pressure due to high nucleation rate at high pressures. The minimum (at 50 mbar) is found to be almost one-fourth of the maximum growth rate (at 20 mbar). In addition, the quality of diamond crystals is gradually improved with the increase of reactor pressure. The optimized pressure for well faceted diamond polycrystals is 30 mbar. At this pressure, electrical resistivity of diamond films is also low. Grain size, grain density, FWHM and growth rate all show an oscillatory behavior with the increase of pressure. However, resistivity decreases rapidly at low pressures due to large sized diamond crystals of lower density and decreases slowly with further increase of pressure by suppressing diamond grain growth, hence increasing the grain density and the grain boundary area. A fall in electrical resistivity of about 3 orders of magnitude (from $10^{9}$ to $10^{6} \Omega \mathrm{cm}$ ) is observed with increase in reactor pressure. This result suggests that such low resistive diamond films can be used for semiconductor applications. From the observed facts, it can be concluded that the present results obtained through SEM, XRD, the Raman spectroscopy and even through electrical resistivity almost support each other.

\section{Acknowledgments}

This work was supported by Higher Education Commission (HEC) of Pakistan under International Research Support Initiative Program (IRSIP).

\section{References}

[1] R.F. Davis, Diamond Films and Coatings, Noyes Publications, Park Ringe (NJ) 1992.

[2] K.E. Spear, J.P. Dismukes, Synthetic Diamond: Emerging CVD Science and Technology, Wiley, New York 1993.

[3] Z.L. Wang, C. Lu, J.J. Li, C.Z. Gu, Appl. Surf. Sci. 255, 9522 (2009).

[4] M. Ullah, E. Ahmed, Current Appl. Phys. 12, 945 (2012).

[5] Y. Okumura, K. Kanayama, K.-I. Shogaki, Combust. Flame 157, 1052 (2010).

[6] M. Zhang, Y. Xia, L. Wang, B. Gu, Q. Su, Y. Lou, J. Cryst. Growth 274, 21 (2005).
[7] A.T. Collins, E.C. Lightowler, in: Properties of Diamond, Ed. J.E. Field, Academic Press, San Diego 1979.

[8] N. Jiang, K. Nishimura, Y. Shintani, A. Hiraki, J. Cryst. Growth 255, 102 (2003).

[9] G.H. Chen, R.Q. Cai, X.M. Song, J.X. Deng, Mater. Sci. Eng. B Solid State Mater. Adv. Technol. 107, 233 (2004).

[10] S.H. Seo, T.H. Lee, Y.D. Kim, C.K. Park, J.S. Park, Thin Solid Films 447, 212 (2004).

[11] H. Rau, F. Picht, J. Mater. Res. 7, 934 (1992).

[12] D.W. Kweon, J.Y. Lee, D. Kim, J. Appl. Phys. 69, 8329 (1991).

[13] M.M. Larijani, A. Navinrooz, F. Le Normand, Thin Solid Films 501, 206 (2006).

[14] S.F. Wang, Y.R. Wang, J.C. Pu, J.C. Sung, Thin Solid Films 498, 224 (2006).

[15] T.D. Makris, R. Giorgi, N. Lisi, L. Pilloni, E. Salernitano, Diamond Relat. Mater. 14, 318 (2005).

[16] S. Pecoraro, J.C. Arnault, J. Werckmann, Diamond Relat. Mater. 14, 137 (2005).

[17] S.T. Lee, Y.W. Lam, Z. Lin, Y. Chen, Q. Chen, Phys. Rev. B 55, 15937 (1997).

[18] J. Kang, C. Xiao, Y. Xiong, Y. Wang, Q. Meng, Z. Lin, K.A. Feng, Diamond Relat. Mater. 9, 1691 (2000).

[19] Q. Yang, W. Chen, C. Xiao, R. Sammynaiken, A. Hirose, Carbon 43, 748 (2005).

[20] L.S. Wang, C.H. Wang, C.W. Peng, C.Y. Lee, H.T. Chiu, Carbon 43, 2618 (2005).

[21] J.A. Smith, M.A. Cook, S.R. Langford, S.A. Redman, M.N.R. Ashfold, Thin Solid Films 368, 169 (2000).

[22] T. Hao, H. Zhang, C. Shi, G. Han, Surf. Coat. Technol. 201, 801 (2006).

[23] S. Schwarz, S.M. Rosiwal, M. Frank, D. Breidt, R.F. Singer, Diamond Relat. Mater. 11, 589 (2002).

[24] Y.A. Mankelevich, A.T. Rakhimov, N.V. Suetin, Diamond Relat. Mater. 5, 888 (1996).

[25] D.G. Goodwin, J. Appl. Phys. 74, 6888 (1993).

[26] J.C. Angus, E.A. Evans, in: The Physics of Diamond, Eds. A. Paoletti, A. Tucciarone, IOS Press, Amsterdam 1997, p. 31.

[27] J. Filik, Spectro. Eur. 17, 10 (2005).

[28] L.J. van der Pauw, Philips Res. Rep. 13, 1 (1958).

[29] S. Yang, Z. He, Q. Li, D. Zhu, J. Gong, Diamond Relat. Mater. 17, 2075 (2008).

[30] X. Liang, L. Wang, H. Zhu, D. Yang, Surf. Coat. Technol. 202, 261 (2007).

[31] K.L. Hanson, Acta Metall. 27, 515 (1979).

[32] K.K. Hirakuri, T. Kobayashi, E. Nakamura, N. Mutsukura, G. Friedbacher, Y. Machi, Vacuum 63, 449 (2001).

[33] K.K. Hirakuri, M. Yoshii, G. Friedbacher, M. Grasserbauer, Diamond Relat. Mater. 6, 1031 (1997).

[34] S.M. Leeds, T.J. Davis, P.W. May, C.D.O. Pickard, M.N.R. Ashfold, Diamond Relat. Mater. 7, 233 (1998).

[35] F. Jia, Y. Bai, F. Qu, J. Zhao, C. Zhuang, X. Jiang, Vacuum 84, 930 (2010). 
[36] A.K. Kulkarni, A. Shrotriya, P. Cheng, A. Rodrigo, R. Basyam, D.J. Keeble, Thin Solid Films 253, 141 (1994).

[37] K. Chakrabarti, R. Chakrabarti, S. Chaudhuri, A.K. Pal, Diamond Relat. Mater. 7, 1227 (1998).

[38] M. Adamschik, R. Muller, P. Gluche, A. Fluter, W. Limmer, R. Sauer, E. Kohn, Diamond Relat. Mater. 10, 1670 (2001).
[39] R. Brunsteiner, R. Haubner, B. Lux, Diamond Relat. Mater. 2, 1263 (1993).

[40] S.J. Harris, A.M. Weiner, J. Appl. Phys. 75, 5026 (1994). 